\title{
Recent Activities of International Education in IGSES at Kyushu
}

\section{University}

\author{
Associate Professor, Dr. Osama Eljamal \\ Interdisciplinary Graduate School of Engineering Sciences (IGSES), Kyushu University, 6-1 Kasuga-Koen \\ Kasuga, Fukuoka, Japan, 816-8580
}

\begin{abstract}
This paper updates the status of international education in IGSES at Kyushu University and provides future directions for expected international projects. Interdisciplinary Graduate School of Engineering Sciences (IGSES) is part of the Kyushu University (KU), which provides academic and professional programs in a wide range of areas, including material, energy and environment. IGSES was established in 1979 as the nation's first independent graduate school from undergraduate schools for the interdisciplinary research and education in science and engineering. The current IGSES consists of five departments and plays an important role of advanced research and education in the three main fields, namely, material, energy and environment with the cooperation of Institutes for Materials Chemistry and Engineering (IMCE) as well as Research Institute for Applied Mechanics (RIAM). The paper summarizes an international education in IGSES by describing each of the programs of Intellectual Exchange and Innovation Program (IEI Program), The Advanced Graduate Program in Global Strategy for Green Asia (GA program), CAMPUS Asia program (CA program), Global-30 Master Program (G30 Program) and Super Global University Project (SGU)
\end{abstract}

Keywords: IGSES; International Education; IEI Program; GA program; CA program; G30 Program; Super Global University Project

\section{Intellectual Exchange and Innovation Program (IEI Program)}

The IEI program has started in October 2014 as a newly doctoral program to provide a high-tech training academy for talented young people to become the future distinguished academics of South East Asia, the Middle East, and North Africa. IEI program student has to earn at least 16 credits including 14 compulsory credits as well as complete a doctoral thesis approved by faculty committee. The IEI program is financially supported by the Japanese Ministry of Education, Culture, Sports, Science and Technology (MEXT). The program is designed for 20 exceptional students including 10 students in excellent standing will be awarded a scholarship for three years. First batch students of IEI program were enrolled into IGSES in October 2014 and the screening of second batch finished and successful students will enroll into IGSES in October 2015.

\section{The Advanced Graduate Program in Global Strategy for Green Asia (GA program)}

Green Asia program (GA program) has started since November 2012 as an innovative education course for talented 
graduate students which provide an exceptional opportunity combining both a Masters and Ph.D. Only 20 exceptional students including 10 Japanese and 10 international are allowed to enroll in the GA program each year. Successful candidates have the opportunity to be trained in one of the program's three specialized fields: materials science, system engineering, and resources engineering, with additional lectures on environmental science, basic sociology, and economics. The GA program is one of the Japan Society for the Promotion of Science JSPS-MEXT program for leading graduate schools, which is planned to develop exceptional leaders who can contribute to the achievement of Green Asia. The Green Asia Program is a five-year program integrating master and doctoral courses; Figure 1 shows educational system and curriculum in the GA Program. The management organization of GA Program is shown in Figure 2 which describes the connection and collaboration between Green Asia center and several departments and institutions in Kyushu University.

\section{CAMPUS Asia program (CA program)}

CAMPUS Asia program (CA program) has launched in October 2011 as an international double degree program jointly by Kyushu University (Japan), Shanghai Jiao-Tong University (China), and Pusan National University (South Korea). CA program is Collaborative Graduate School Program for Global Human Resources Development in Energy and Environmental Science and Technology with the aim to grow qualified researchers and engineers who can be active leaders in the field of science and technology of energy issue and related environmental issue,' Energy and Environmental Science and Technology' (EEST).

The primary concern of the program is master course. This master course program includes an international collaboration with mutual partnership and consisting of an energy and environment science and technology (EEST) curriculum, and a research work for master thesis. CA program is also financially supported by MEXT, with a five years graduate school program entitled "Collaborative Graduate School Program for Global Human Resources Development in Energy and Environmental Science and Technology"(FY2011-2015).

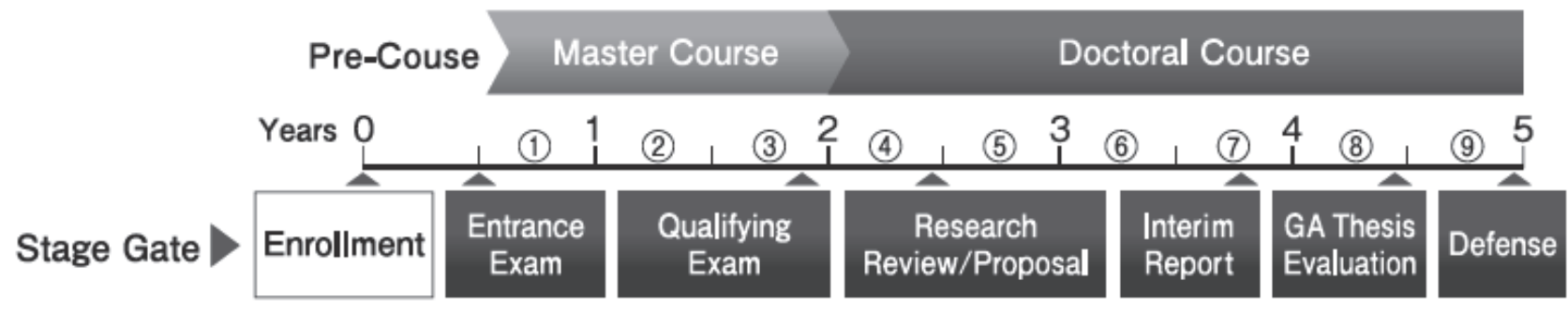

5-year joint Masters/Ph.D. Program

Program begins 6 months after April enrollment

Learning and Growing Together

Japanese and international students (in $1: 1$ ratio) of 20 in total are placed in each class year

Financial Aid : Scholarship is provided

Figure 1. Educational System and Curriculum in the Green Asia Program 


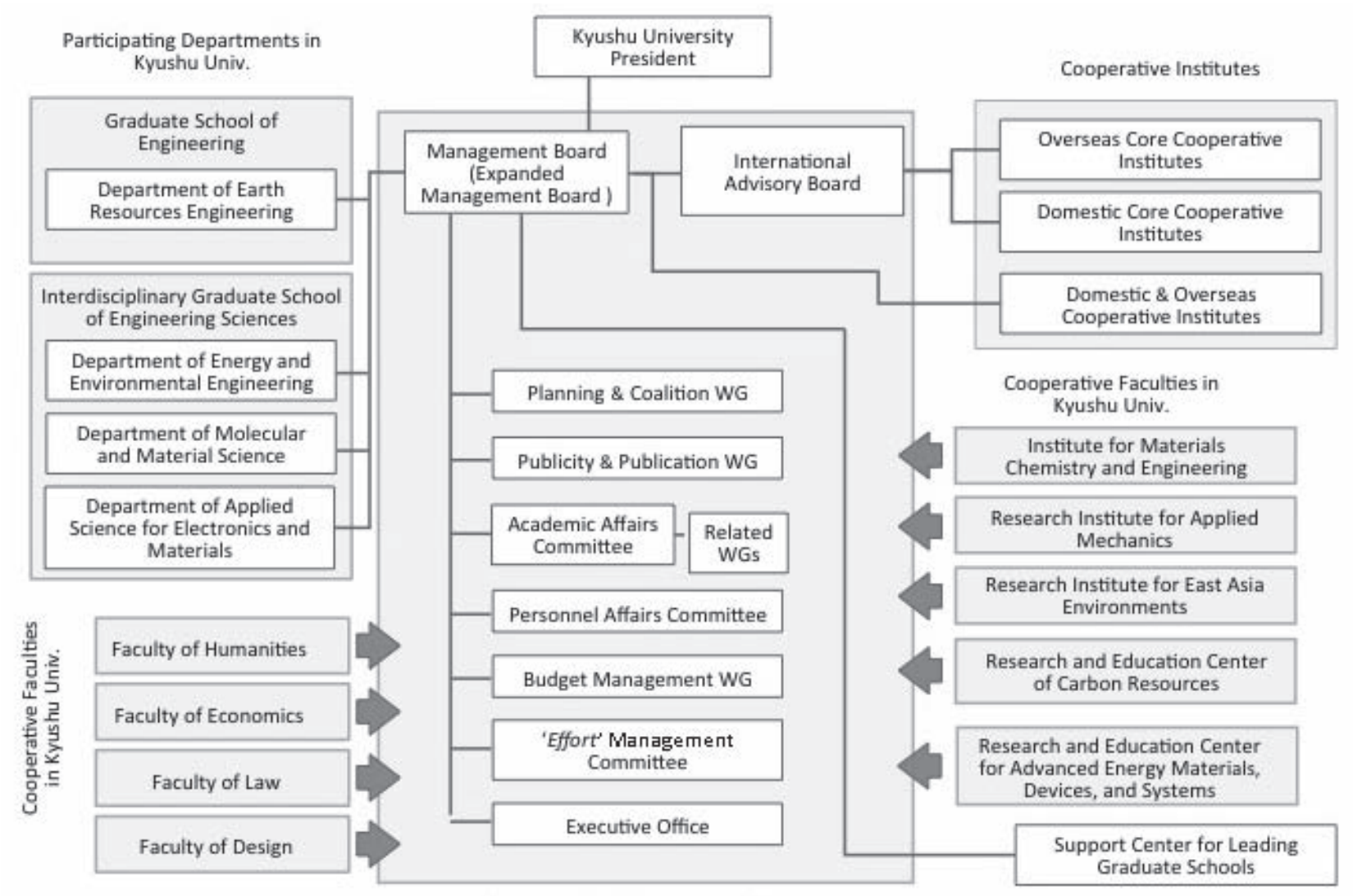

Green Asia Education Center

Figure 2. Management Organization of Green Asia Program

For the fulfilment of international double degree program of CA, Interdisciplinary Graduate School of Engineering Sciences at KU establishes a new master's course, “International Energy-Environment Science and Technology (EEST) course", fully managed by English language. This international course includes curriculum with particular emphasis on EEST, providing internship course, problem solving course, and technician and researcher ethics course together with two intense Summer schools. The exchange student will study for one semester at either SJTU or PNU. When the degree requirements are fulfilled at the Two Universities, the exchange student shall be awarded the Master degrees from the Two Universities. Figure 3 shows the Study pattern of double degree for Kyushu University students.

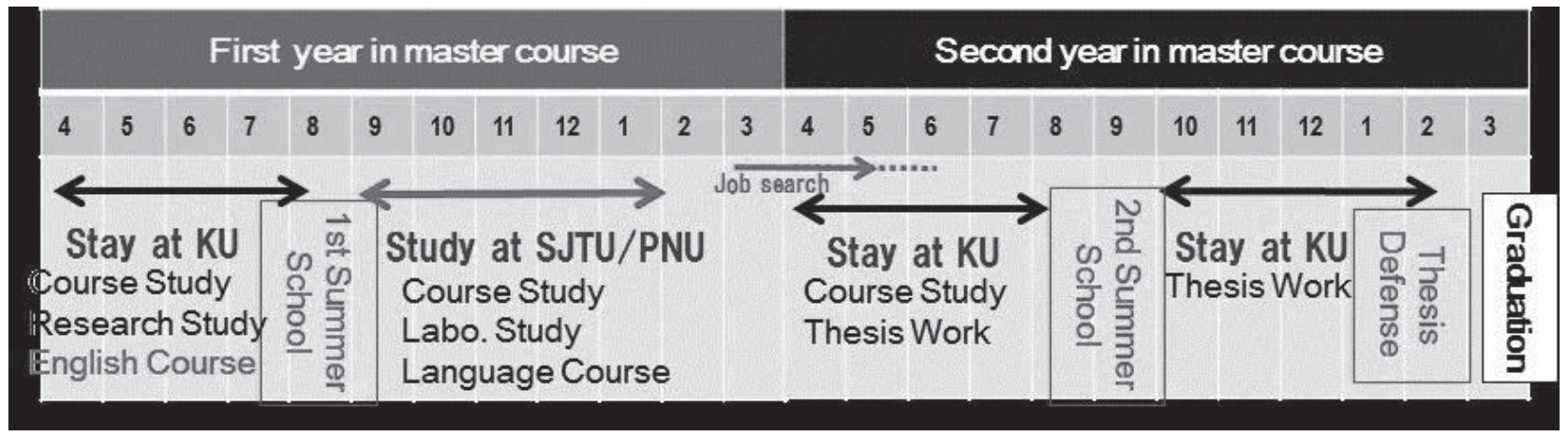

Figure 3. Study pattern of double degree for Kyushu University students 


\section{Global-30 Master Program (G30 Program)}

G30 program has started since April 2009 in order to further promote the globalization of higher education in Japan, Kyushu University was chosen as a member G30 Program, which planned and funded by Japan's Ministry of Education, Culture, Sports, Science and Technology (MEXT). IGSES as a part of Kyushu University involved in this program by provide specially designed program for international students who wish to acquire an in-depth knowledge of symbiotic technology, and provides them with the know-how to further their ability to explore and resolve the world's pressing energy and environmental problems. Students in the program are able to take advantage of the close guidance of a team of supervisors, along with state-of-the-art research facilities.

\section{Super Global University Project (SGU)}

Kyushu University has been selected by the Ministry of Education, Culture, Sports, Science and Technology (MEXT) for the 2014 Top Global University Project as one of Japan's top universities providing a world-class level of research and education (Type A).

The Super Global University Project aims to bolster the international competitiveness of Japanese higher education by providing priority support to universities dedicated to thorough internationalization and university reform.

IGSES as a part of Kyushu University will involve in this project by several means, as a starting step IGSES is going to strengthening the international relationship with Malaysia-Japan International Institute of Technology (MJIIT). MJIIT which is an overseas core partner in the program of leading graduate school by IGSES had been agreed to establish our office there.

Another step under the umbrella of Super Global University Project IGSES envisages Bangladesh Japan International Institute of Technology modeling after MJIIT established in Malaysia by Japanese ODA. Currently, we are working on the department of education and cabinet office in Bangladesh with setting Dhaka University as a counterpart, and planning and preparing to submit the scheme of official development assistance and technical cooperation (grand aid) in FY 2018 by Japanese government from the Ministry of foreign affairs of Bangladesh to the Ministry of foreign affairs of Japan with the cooperation of JICA.

This integrated degree program from a master's course to second stage of a doctoral course is 7 years long instead of 5 years. Admission capacity of program is 100 students per year, first 4 years the students will study in Dhaka and the rest of 3 years (doctoral course) students will move to Kyushu University. As a first step, Kyushu University and Dhaka University will work together, and it will lead to the graduate school of the consortium of universities.

\section{References}

1. IEI program committee, Intellectual Exchange and Innovation Program (IEI Program) Guidelines, 2015.

2. Green Asia committee, Kyushu University Program for Leading Graduate Schools Advanced Graduate Program in Global Strategy for Green Asia, Activity report 2012-2013.

3. Yasutake Teraoka, Introducing the program entitled CAMPUS-Asia EEST, "Collaborative Graduate School Program for Global Human Resources Development in Energy and Environmental Science and Technology, 2013.

4. Interdisciplinary Graduate School of Engineering Sciences website, http://www.tj.kyushu-u.ac.jp/en/index.html 


\section{Biography}

Osama Eljamal is an Associate Professor of Interdisciplinary Graduate School of Engineering Sciences at Kyushu University. His main research interests are water treatment; the following are his previous experience and education:

- Associate Professor,

Interdisciplinary Graduate School of Engineering Sciences, Kyushu University, Japan, April 2014 - Present.

- Associate Professor,

Graduate School of Bioresource and Bioenvironmental, Kyushu University, Japan,

October 2010 - March 2014.

- Visiting Scholar,

Department Chemical Engineering, University of Waterloo, Canada,

June 2011 - September 2011.

- Postdoctoral Fellow,

Department Earth Resources Engineering, Kyushu University, Japan,

April 2009 - October 2010.

- Ph.D. in Environmental Engineering

Department of Urban and Environmental Engineering, Kyushu University, Japan

April 2006 - March 2009

- M.S. in Environmental Engineering

Department of Urban and Environmental Engineering, Kyushu University, Japan

April 2004 - March 2006

- B.S. in Civil Engineering

Department of Civil Engineering, IUG, Palestine

September 1992 - June 1997 